\title{
DIE VROEGSTE HEIDENBERIG OOR CHRISTUS EN DIE CHRISTENE.
}

Hoewel nie in die gewone sin van die woord nie, kan nogtans van Julie 64 n.C. gepraat word as die vroegste datum waarop die Romeinse staat ,erkenning" gegee het aan die Christendom.

Voorheen vaagweg beskou as een of ander Joodse sekte.") word die Christendom deur die Romeinse geskiedskrywer, Publius Cornelius Tacitus, met noem van naam verbonde aan die groot brand wat in Rome uitgebreek het. tydens die regering van Nero, in die nag van 18 Julie 64 n.C.; as stigters van die brand wat ongeveer nege dae gewoed het en tien van die veertien stadsdistrikte in puin gelê het, het die owerheid. in die persoon van die keiser, die Christene in die stad tot verantwoording geroep en met die mees gerafineerde wreedhede gestraf.

Tacitus se Annales 15.44, is belangrik vir die vroeë geskiedenis van die Christendom, nie net omdat dit die vroegste heidenberig oor Christus en die Christene is nie, maar ook omdat dit $n$ aanvulling is vir ons kennis oor ' $\mathrm{n}$ betreklik duistere stukkie van die geskiedenis, $\mathrm{nl}$. die van die eerste Christelike gemeente in Rome.

Die betrokke passage maak deel uit van die skildery wat Tacitus ons voorhou van Nero, wie se gesagsaanvaarding op sewentien-jarige leeftyd in 54 n.C., met blydskap begroet is. Inderdaad is ook die verwagtinge gedurende die eerste vyf jaar van sy regering, toe hy nog

1) Gallio, goewerneur van Achaje. oordeel dit is ... kn kuessie cor in wcord en oor name en oor 'n wet wat vir julle (Jode) geld" Hnd. 18:12-16: Hoofoffi ier Klaudius Lisias sien die Joods-Christelike kontroversie ook as ..twisvrae van hulle (Joodse) wet." Hnd. 23:29. Adv. Tertullıs noem Paulus raas andere dinge, .. n voorstander van die sekte van die Nasaréners." Hnd. 24:5 en 6. 'n De:gelike opinie word deur Festus gehuldig. Hnd. $25: 19$. 
volkome onder die leiding van sy raadgewers, Seneca die Stoïsynse filosoof en Burrus die kommandant van die garde, gestaan het, nie teleurgestel nie. Allerlei misdade, soos die moord op sy stiefbroer, Brittannicus, sy moeder Agrippina en sy eggenote Octavia en uitspatlikhede soos nagboewery, skandelike liefdesawonture en eindelik sy verbintenis met die skone dog listige Poppaea Sabina, het hom al hoe meer in onguns by die volk laat kom. Roekelose konskripsies en teregstellinge onder hulle geledere, het hom die haat van die aristokrasie op die hals gehaal. Toe op die nag van die 18 de Julie 64 n.C. n groot brand uitbreek in die Circus Maximus, snel oor die stad uitbrei en twee-derdes daarvan in as laat, is Nero algemeen verdenk as die kwaadwillige oorsaak daarvan. Gerugte het in omloop gekom dat hy self die brand beveel het, dat hy tydens die brand, genietend van die skouspel, op 'n verhoog gestaan het en sy gedig. ,Die val van Troje," voorgedra het. Verdere rede vir verdenking was die feit dat die keiser so gou klaar was met nuwe planne vir die heropbou van die stad; die gerug wou dat hy die ou stad verwoes het met die doel om 'n nuwe, na hom genoemde, op te trek.

Tacitus, wat 'n getroue relaas gee van al die gerugte, is egter nie bereid om die waarheid daarvan te onderskryf nie; dit kon ewe goed toevallig gebeur het. $\left.{ }^{2}\right)$ Maar wie en wat ook al die oorsaak van die brand was, alle verdenking het op die Keiser gekonsentreer; trots elke populêre maatreël, soos offers aan die gode en kwistige geskenke om die lot van die dakloses te verlig, het die gerugte dat Nero die brandstigter was. hardnekkig aangehou. Dit moes ten alle koste beëindig word.

Wat Nero ten slotte, en dit wil voorkom met 'n mate van sukses, as bliksem-afleier gebruik het, deel Tacitus kortliks maar tog, in sy karakteristiek kernagtige styl, gedetailleerd mee:

.Om dus die gerug vir goed te beëindig het Nero die skuld geskuif en die mees gerafineerde strawwe toegepas op mense wat gehaat was deur hul skanddade en deur die volk Christene genoem is. Die naam is afkomstig van Christus wat tydens die regering van Tiberius deur die procurator Pontius Pilatus tereggestel is; hoewel vir daardie oomblik onderdruk, het die verderflike bygeloof weer uitgebreek - nie net in Judea, die oorsprong van die kwaad, nie - maar selfs in die hoofstad, waarheen van heinde en verre alle gruwelikhede en skandelikhede saamvloei en druk beoefen word. Heel eerste is dan voor die gereg gebring die wat erken het en daarna, op grond van hulle aanwysing, is $n$ groot menigte veroordeel, nie soveel op aanklag van brandstigting nie, as wel weens haat teen die menslike geslag. En met die sterwendes

$\left.{ }^{2}\right)$ Brande was in Rome nie 'n seldsaamheid nie. Onder Tiberius se regering, in 27 en weer in $37 \mathrm{n} . \mathrm{C}$. is groot skade aangebring deur brande. (Tac. Ann. 4.64, 1 en $2 ; 4.45,1$ en 3$)$. 
is bowendien nog die spot gedryf : met die velle van wilde diere oordek is hulle deur honde verskeur of aan kruise geslaan of in die vlamme verteer en na sonsondergang is hulle, vir die doel van nagtelike verligting, verbrand.

Nero het sy park geleen vir hierdie skouspel en 'n voorstelling van wedrenne gegee terwyl hy homself onder die volk vermeng het in die kleredrag van ' $n$ menner of op 'n renwa geklim het. Daardeur is medelye gewek; al het dit ook skuldiges gegeld wat voorbeeldige strawwe verdien het, is tog gevoel dat hulle gedood word, nie in die belang van die gemeenskap nie, maar terwille van die moordlus van één man." ${ }^{3}$ )

Die historiese waarde van die mededeling is afhanklik van die egtheid daarvan; grond vir betwyfeling van die egtheid word gebied deur die feit dat interpolasies ") in die werke van vroeë Christelike skrywers en selfs hele korrespondensizs.") wat vervals is om 'n Christelike strekking te dra, nie ontbreek nie. Daarom het die hiperkritiese P. Hochart ${ }^{6}$ ) hierdie berig ook as vals bestempel maar $c p$ baie swak gronde. 'n Onlangse bestryding deur Hartman, ${ }^{7}$ ) is oortuigend weerle deur Alfons Kurfess. ${ }^{8}$ )

Die egtheid van die stuk, wat hedendaags algemeen aangeneem word, kan ook onbetwisbaar gehandhaaf word op grond van inwendige getuienis.

In die eerste plek is dit ondenkbaar dat ' $n$ vervalser hom só presies sou kan inleef in die sienswyse van Tacitus se eeu. Tacitus spreek daadwerklike veragting vir die Christendom uit. Dit sal $n$ vervalser. veral in laat-Christelike vervalser nie kon regkry nie. Vernaamlik pleit egter vir die egtheid die sinsbou en woordkeus wat tiperend van

3) Die Latynse teks word hier weergegee omdat van tyd tot tyd daarna verwys sal word. Tac. Ann. 15.44. ergo abolendo rumori Nero subdedit reos et quaesitissimis poenis adfecit, quos per flagitia invisos vu'gus Christianos appellabat, auctor nominis eius Christus Tiberio imperante per procuratorem Pontium Pilatum supplicio adfectus erat; repressaque in praesens exitiabilis superstitio rursum erumpebat, non modo per Judaeam, originem eius mali, sed per urbem etiam, quo cuncta undique atrocia aut pudenda confluunt celebranturque, igitur primum correpti qui fatebantur, deinde indicio eorum mu titudo ingens haud proinde in crimine incendii quam odio humani generis convicti sunt, et pereuntibus addita ludibrja, ut ferarum tergis contecti laniatu canum interirent, aut crucibus adfixi aut flammandi, atque ubi defecisset dies in usum nocturni luminis urerentur. hortos suos ei spectaculo Nero obtulerat et circense ludicrum edebat, habitu aurigae permixtus plebi vel curriculo insistens. unde quamquam adversus so tis et novissima exempla meritos miseratio oriebatur, tamquam non utilitate publica sed in saevitiam unius absumerentur.

4) Josephus Antiq. 18.3.3 - of heeltemal vervals of onherkenbaar geinterpoleer.

5) Die sg. Seneca-Paulus-korrespondensie. 'n Breedvoerige bespreking daarvan word gegee deur Lightfoot. Dissertations on the Apostolic Age, London 1892, p. $317-322$.

6) P. Hochart. Études au sujet de la persécution des Chrétiens sous Nero, Paris 1885.

7) Mnemosyne XLIV (1916) p. 343 ff en XLVII (1919) p. 246 ff

8) Mnemosyne, Tertia Series. Volumen Sextum (1938), p. $261 \mathrm{ff}$. 
Tacitus is; die woord "subdedit" kom bv. vyftien maal in sy werke voor, en dan nege maal met die betekenis wat dit hier het - nl. subdere, „op valse gronde inskuif." Op die betekenis van die woord word weldra weer teruggekom.

Verder het Sulpicius Severus. 'n christelike skrywer uit die begin van die vyfde eeu, wat woorde van 'n onverdagte stuk van Tacitus (Ann. 15.37.8) gebruik, ook 'n deel van hierdie berig oorgeskryf.")

n Ander moontlikheid is dat Tacitus. wat die geskiedenis ruim vyftig jaar '") nadat dit plaasgevind het beskryf, in sy oordeel deur latere gerugte oor die Christene beïnvloed is en dus 'n onbetroubare weergawe bied. Maar blykens sy Agricola 3.4 het hy die materiale vir die opstel van die Annales in 97-98 n.C. al in orde gehad. Buitendien moes hy ten tyde van die brand al 'n knapie van tien jaar oud gewees het, sodat hy moontlik 'n ooggetuie daarvan was.

Daar is ook minder belangrike teksmoeilikhede in die passage, wat egter nie aan vervalsing nie maar aan die gewone verwering waaraan manuskripte onderhewig is, gewyt moet word. ")

Is eenmaal die egtheid van die berig vasgestel, vloei daaruit ' $n$ paar hoogsbelangrike vrae voort:

a. Was daar in 64 n.C. soveel Christene in Rome dat hul optrede in die ooglopend was en Tacitus hul kon beskryf as $n$ "multitudo ingens"?

b. Was die Christene daadwerklik die brandstigters?

c. Indien nie, hoe kom Nero daartoe om hulle die misdaad aan te vryf?

Oor die eerste vraag: Nóg die nuwetestamentiese Geskrifte nóg dié buitebybelse geskrifte van die eerste eeue bied enige direkte aanwysing betreffende stigting, samestelling en getalsterkte van die gemeente. Indirekte aanwysinge is daar egter genoegsaam voorhande om in paar waarskynlike gevolgtrekkinge te maak.

Die vroegste dokumentêre bewys vir die bestaan van in gemeente in die hoofstad is die Brief aan die Romeine wat Paulus, volgens die vernaamste Kommentatore. ${ }^{12}$ ) vroegstens in 54 en laatstens in 58 n.C. op sy derde sendingsreis uit Korinthe geskryf het. Self was hy nie

9) Sulp. Sev. Chron. 2.29 vertoon 'n byna woordelike ooreenkoms met Ann. 15.44 5 en 6.

10) Tacitus, gebore in ongeveer 54 n.C., voltooi die Annales tydens die regering van Trajanus in 115-116 n.C.

11) Die text. Med. gee die lesing, ..aut crucibus adfixi aut flammandi atque . .." wat grammatikaal onhoudbaar is.

12) Th. Zahn, Grundriss der Einleitung in das Neue Testament. Leipzig 1928. s.36. stel die vervaardiging van die brief teen Pase 58 n.C. So ook Sanday and Headlam, Romans (in I.C.C.) Edinburgh $1930^{13}$. p. xiii. Greydanus. De Brief van den Apostel Paulus aan de Gemeente te Rome (in serie Kommentaar op het N.T.). Amsterdam 1933, bls. 3, stel dit tussen einde 55 en begin 57 n.C. H. Lietzmann. An die Römer (in Hndb. z. N.T.) Tübingen 1933', s. 128, meen die brief is eind 54 n.C. geskryf. 
die stigter van die gemeente nie; die feit dat hy Petrus ook nêrens in die brief noem nie maar inteendeel in opmerking maak soos in Rom. 15:20. maak vir goed in einde aan die middel-derde-eeuse fabel dat Petrus die stigter van die gemeente was. Buitendien verhaal Lukas in die Handelinge alleen Paulus se sendingonderneming na Rome. Dit is onwaarskynlik dat enige ander apostel die stigter van die gemeente was. Tradisie maak etlike interessante maar onbetroubare voorstellings. Dic Latynse weergawe van die Clemensroman ":") noem as stigters enkele reisigers uit Palestina in die tyd van Tiberit's - se'fs nog tydens die lewe van Jesus; in dieselfde jaar sou Barnabas nog vir 'n kort tydjie voor die gemeente opgetree het. Die Griekse oorspronklike van die roman') plaas Barnabas egter in Alexandrieë en gee as stigter aan 'n ongenoemde dissipel van Jesus.

Veel aanneemliker is dat die Christendom na Rome gekom het op dieselfde wyse as na Antiochië en elke ander stad wat 'n sentrum van wêreldverkeer was, $n$ l. deur Jerusalemse Christene wat, na die steniging van Stephanus in $35 \mathrm{n} . \mathrm{C}$., in alle rigtings gevlug het. ${ }^{15}$ ) Lukas noem onder die toehoorders van Petrus op die Pinksterdag ook Romeine." ) Vroeër of later na Rome teruggekeer kon van hulle stellig die eerst? verkondigers van die geloof daar gewees het.

in Baie vername rol in die vroeë bekendmaking van die Christendom te Rome, sal wellig gespeel gewees het deur soldate wat in Judea of ander provinsies gestasioneer was waar die Christendom reeds ingang gevind het; dit is ' $n$ bekende feit dat menige, veral Oosterse. godsdiens met die krygsvolk na Rome gekom het. 'i) Dat die soldate nie onverskillig gestaan het nie teenoor die verkondiging van en aangaande Jesus. blyk genoegsaam uit Luk. 3:14, 7:1-10; Mt. 27:54: Hnd. 10; 13:5-12. Aan die voet van die Palatinus te Rome is in teël gevind waarop 'n figuur met "n eselskop aan 'n kruis gegriffel is. Een of ander soldaat het die volgende woorde daaronder ingekras: "Alexamenos (waarskynlik 'n christen-soldaat) aanbid sy God." ${ }^{1 *}$ )

Effens meer lig as op die stigter, val op ons kennis van die stigtingstyd en die getalsterkte van die gemeente teen 64 n.C., alhoewel ook in verband daarmee met meer waarskynlikhede as sekerhede te werk gegaan moet word.

In sy brief van 55/56 n.C. herhaal Paulus telkemale dat dit al baie jare sy voorneme was om die gemeente te Rome besoek te bring. ${ }^{19}$ ).

13) Clem Recogn. 1. 6-11.

i4) hom. I, 6-12.

15) Hnd. 11:19-25.

16) Hnd. 2:10.

1i) vgl. L. Dushesne. Histoire Ancienne de l'Église tom I. Pari; 1906”. p. 8.

18) vgl. Dr. M. van Rhyn. Het Nieuwe Testament in het Licht der Nieuwere Opgravingen. Amsterdam, 1926, bls. 61 .

19) Rm. $1: 10$ en 11,$13 ; 15: 22$ en 23 . 
As hierdie reeds „baie jare"-oue voorneme van die apostel nie ontstaars" het deur sy ontmoeting te Korinthe met Aquila en Priscilla in $50 \mathrm{n}$.C. nie, dan is dit minstens daardeur aangevuur.

Die bybelse berig van hierdie ontmoeting ${ }^{20}$ ) word angevul deur die heidense geskiedskrywer, Suetonius, wat 'n tydgenoot van Tacitus was. Hy verhaal dat Keiser Claudius ,die Jode wat op aandrywing van Chrestus voortdurend in beroering was, uit Rome verban het." ${ }^{21}$ ) Die edik is in 50 n.C. uitgevaardig. ${ }^{2 " ;}$, Die woorde waarmee Suetonius die toestand van die Jode in Rome ten gevolge van die prediking van Christus omskryf, ,assidue tumultuantes" (voortdurend in beroering) veronderstel nie in eenmalige botsing teen 50 n.C. nie, maar in langdurige wrywing voor daardie tyd.

Dat Aquilla en Priscilla in Korinthe so goed bekend was met dic Evangelie, wys ook op 'n langdurige verkondiging daarvan te Rome voor die verbanningsedik. ${ }^{23}$ ) Daarby noet in aanmerking geneem word dat die gemeente van die hoofstad, by ontstentenis aan die direkte leiding van een van die aposte!s, nie soos die ander gemeentes in 'n jaar of twee nie maar eers na 'n lang tydperk van groei só 'n aktiwiteit en getalsterkte bereik het, dat Joodse reaksie ontstaan het. Só gesien, moes daar aan die Keiserlike edik, volgend op die onluste tussen Jode en Christene, ruim vyf jaar voorafgegaan het; dit stel die ontstaansdatum van die gemeente laatstens op $45 \mathrm{n}$.C. vas.

Aan die anderkant kon die gemeente moeilik voor 40 n.C., d.w.s. vyf jaar na die steniging van Stéphanus, $\left.{ }^{21}\right)$ tot stand gekom het. Die vroegste moontlike draers van die Christendom na Rome was die Romeinse Jode wat op die Pinksterdag en met die steniging van Stéphanus in Jerusalem was. Terwyl egter lede van die Synagoge van die Libertyne ${ }^{25}$ ) van die aanleidende veroorsakers van die steniging en die vervolginge was, is dit moeilik denkbaar dat die vlugtelinge uit

20) Hind. $18: 2$.

21) Suet. se werk in 120 gepubliseer. De Vita Caesarum. Claudius c. 25 : „(Claudius) Indaeos' impulsore Chresto assidue tumultantes Roma expulit'. Dat met Chrestus, Christus bedoel word blyk daaruit dat Tertullianus (Apol. 3 cf. Justin. Apol. 1 en 3) die heidene teregwys op hul verkeerde uitspraak van Christiani as Chrestiani.

22) Orosius. Hist. adv. Paganos. 7, 6-15 stel dit op 49 n.C. Vgl. ook Obbink en Brouwer, Inleiding tot den Bijbel, Amsterdam. 1928. bls. 262, en Feine-Behm. Einleitung in das Neue Testament: Leipzig, 1936, s. 121.

23) Dr. A. van Veldhuizen. Paulus en zijn Brief aan de Romeinen (serie Tekst en Uitleg), Gron. $1927^{3}$, b.s. 52 ff. meen dat die egpaar eers na die verbanning Christene geword het. Indien dit die geval was, is dit onbegryplik dat hulle so gou met Paulus in Korinthe meegewerk het. Kort daarop openbaar hulle teenoor Apollos so 'n grondige kennis van die Christelike geloof dat hulle dit duidelik lank voor die tyd moes beoefen het. (Hnd. 18:24-26).

$\left.{ }^{2}\right)$ vgl. Feine-Behm, Einleitung in das Neue Testament, Leipzig, 1936 s. 121. Sien egter ook Obbink-Brouwer, Inleiding tot den Bijbel, Amsterdam, 1928, bls. 262.

${ }^{25)}$ Prof. J. de Zwaan, De Handelingen der Apostelen (serie Tekst en Uitleg), Gron. 1920 , bls. 85 , verkies om vir Libertini te lees die minder waarskynlike konjektuur van Gothofried. Libystini. 
Jerusalem hulle al dadelik sou gewend het na die oorsprong van die Libertynse Synagoge, die Jode in Rome. Aan die heidene te Rome kon die Evangelie ook nie so heel vroeg verkondig gewees het nie, daar dit voor 43/44 n.C. beleid was om dit alleen aan Jode bekend te maak. ${ }^{26}$ ) In verband met al hierdie gegewens kan die ontstaantyd van die gemeente dus gestel word in die tydperk 40 tot 45 n.C. ${ }^{27}$ )

Wanneer Tacitus die Christen-martelare in $64 \mathrm{n}$.C. as 'n ,,multitudo ingens" (groot menigte) beskryf, hoef dit dus nie 'n retoriese oordrywing te wees nie. Die gemeente van die hoofstad was teen daardie tyd al ruim twintig jaar oud. Agt jaar tevore was hul geloof, volgens Paulus se brief, reeds in die hele wêreld verkondig. ${ }^{28}$ ) Teen 58 n.C. kom die apostel as gevangene na Rome en word onderweg te Puteoli gasvry ontvang deır Christene; uit die feit dat broeders hom tegemoet kom uit die hoofstad tot by Forum Appii en Tres Tabernae skep hy moed. ${ }^{29}$ )

Dit wil voorkom asof die Evangelie in die vorige jaar ook al deurgedring het tot die hoër stande; volgens Tacitus is Pomponia Graecina, 'n gesiene dame, in 57 n.C. skuldig bevind op aanklag van ,.superstitiones externae." Dat die ,vreemde bygeloof" die Christelike geloof was, blyk nie alleen uit Tacitus se beskrywing van haar gedrag nie, maar ook uit die christelike katakombe-inskrifte van Pomponius Bassus en Pomponius Graecinus, haar latere familie. ${ }^{30}$ )

Die prediking van Paulus, van wie die oorlewering meedeel dat hy saam met Petrus tydens die vervolginge van Nero gesterf het, sal te Rome die aantal Christene aanmerklik laat vermeerder het. ${ }^{31}$ )

Daar is reeds op gewys dat die Jode van die hoofstad so vroeg as $50 \mathrm{n.C}$. al in reaksie gekom het, omdat toe al die toename van die Christene ten koste van hulle dertig- tot veertigduisend ledetal onrusbarend geword het.

26) Hnd. 11:9. vgl. Obbink-Brouwer, a.w. bls. 262.

27) Th. Zahn, Der Brief des Paulus an die Römer. Leipz. $1925^{3}$, s. 10, na aanl. van Rom. 13:11 en 'n mededeling van Porphyrius, by Augustinus, Epist. 102.8 aangehaal, stel dit op 37-40 n.C.

28) Rom. 1:8. Van Rom. 16 en Fil. 1:13, 4:22 word nie gebruik gemaak as bewysmateriaal nie, omdat baie gegewens daarop dui dat e.g. hoofstuk nie by die Romeine brief hoort nie; die Filipense-brief hoef nie noodwendig uit Ro $e$ geskryf te gewees het nie; die woord wat in Fil. 1:13 voorkom en vertaal is met "keiserlike lyfwag." kan ewegoed beteken .gcewerneurswoning" soos dit ook in Mt. 27:35 vertaal is; wat in Fil. 4:22 vertaal word met ,.keiserlike he is." kan beter weergegee word deur ,imperiale kantore". vgl. Duncan. St. Paul's Ephesian Ministry, London, 1929, p. $68 \mathrm{ff}$ en $108 \mathrm{ff} ; \mathrm{K}$. and S. Lake, An Introduction to the New Testament, London, 1938, p. 107; ook Eusebius, Hist. Ecci. III. 3-6.

29) Hnd. 28:13-15, Hnd. 28:22b dui nie op die onbekendheid en onbenulligheid van die sekte nie, maar eerder op die teenoorgestelde: ,dit weet ons egter wat hierdie sekte betref, dat dit oral weerspreek word," vgl. Blass-Detrunner Gramm. des neutest. Griechisch. Gött. $1913^{4}$ s. 260.

30) vgl. Furneaux. The Annals of Tacitus, vol. II. Oxf. 1907, p. 195.

si) Hnd. $28: 30$ en 31 . 
Hoewel die metode van Gibbon se berekening weinig verband het met die saak self, sal sy slotsom, dat die Christengemeente in Rome in 64 n.C. 7,000 lidmate getel het, ${ }^{32}$ ) in die !ig van wat hierbo gesê is, nie vêr van die waarheid wees nie.

In nou samehang met die tweede vraag. of die Christene daadwerklik die brandstigters w'as, staan die beveerde aans:ootlikheid van hul belydenis en praktyke.

Dit is duidelik dat Tacitus, wanneer hy die Christene beskryf as "mense wat weens hul skanddade gehaat is" (per fagitia invisi), nie uit eie waarneming put nie maar uit publieke opinie. Plini:s Secundus, wat 'n paar jaar voor Tacitus skryf. in brief 96 van sy !-orrespondensie met Keiser Trajanus, gebruik ook die uitdrukking t.o.v. die Christene - dat ,,skandade hul naam aankleef" ":3) en dat hul godsdiens ,onsedelik en uitspatlik" "') is.

Blykens die brief van Plinius asook die weerlegginge van die apologete tit die tweede eeu $\left.{ }^{\prime \prime \prime}\right)$, word die Christene algemeen verdink van kannibalisme, bloedskande en kindermoord - natuurlik weens 'n wanbegrip van hul sakramentele gebruike.

Tacitus se bestempeling van die Christelike ge'oof. as n ,,verderflike bygeloof" (exitiabilis superstitio) het sy grond daarin dat vir die Romein alle nie-Griekse godsdienste ..superstitio "is; ${ }^{36}$ ) hy noem die "superstitio" egter ,exitiabilis" (verderflik); die woord gebruik hy ook in Ann. 16.5.2 van siekte. Die Christelike geloof is dan vir die karakter van die Romeinse burger wat siekte vir die menslike liggaam is slopend. Suetonius kwalifiseer die „superstitio" as ..nova ac malefica" (vreemd en misdadig) ${ }^{37}$ ) ongetwyfeld in aansluiting by die populêre opinie soos hierbo vermeld.

Verder, die gearresteerde Christene is in die brandstigtingsproses, volgens Tacitus, veroordeel weens ..haat teen die menslike geslag" (odio humani generis); die ,,menslike geslag" is eenvoudig. die Romeine. Soos hul sakramente aanleiding gegee het vir misverstand van hul gebruike. só word die geloof van die Christene as misanthropiese neigings verklaar; hulle spreek nl. soos Paulus teenoor Felix, ${ }^{38}$ ) van ,.geregtigheid en selfbeheersing en die toekomstige oordeel." Rome is vir die Romein ewig; om te praat van wêreld-einde en wêreld-gerig (en wêreld. ,mundus," is vir die Romein, die Romeinse Imperium) kan maar een oorsaak hê - haat teen die menslike geslag. As die Christene te

32) Gibbon, Decline and Fall of the Roman Empire, vol. I. (Chandos Library)r p. 374 .

33) flagitia cohaerentia nomin

31) prava et immodica..

35) o.a. Minucius Felix, Octavianus 9; Tertull. Apol. 7 ff.

36) vgl. Tac. Ann. 2.85.5. 3.60.5, 13.32.3.

37) Suet. De Vita Caes. Nero 16.

38) Hnd. 24:25. 
Rome dan nog verder gespreek het in die trant van Rom. 1:18-32, sal hul nie anders as die beskuldiging bevestig het nie. Die opinie sal ook wel versterking gevind het in die sobere, in heidense oog asosiale, lewenswyse van die Christene.

Dit is dus duidelik hoe Tacitus daartoe kom om die Christene aan die einde van hierdie hoogsbelangrike berig te bestempel as .,misdadigers" (sontes) en .,mense wat uiters voorbeeldige strawwe verdien" (novissima exempla meriti).

Terwyl hy as kind van sy tyd die Christene wel as misdadigers beskou, gee Tacitus tog duidelik te kenne dat hulle nie aan die misdaad van brandstigting skuldig is nie; die hele aanklag rus op niks anders nie as Nero se moordlus en sy verpligting om 'n sondebok aan te wys as hy self aan die algemene onguns van die gepeupel wou ontkom. Die sinsnede, ,Nero subdedit reos," wat ons vertaal ,... het Nero as beskuldigdes voorgeskuif..." gee al duidelik die onskuld van die Christene te kenne. Tacitus gebruik die ww. subdēre vyftien maal in sy werke; in ses van die gevalle het dit die letterlike betekenis van. ,een ding onder "n ander te plaas"; in die orige nege gevalle het dit 'n figuurlike betekenis ,om iets wat waar is te vervang met iets wat vals is." $\left.{ }^{39}\right)$ Die sinsnede, .,subdedit reos," uit die pen van Tacitus het dus maar een betekenis: Nero het die Christene valselik voorgestoot as die misdadigers. Trouens hieroor is geen tweeërlei sienswyse moontlik nie wanneer hy nog boënop meld dat , in groot aantal tereggestaan het, nie soseer op aanklag van brandstigting nie. as wel weens haat teen die menslike geslag"; die slotsin van die berig deel mee dat die medelye van die toeskouers by die martelinge gaande gemaak is, gesien dat die mense gedood word nie ten voordele van die publieke veiligheid nie, maar ter versadiging van die moordlus van Nero.

Wat met die eerste oogopslag lyk na in erkenning van skuld aan die brandstigting deur die Christene, is die woorde, heel eerste is dan voor die gereg gebring die (Christene) wat erken het.... (igitur primum correpti qui fatebuntur....). Wat die Christene erken het, is nie aandadigheid aan die brandstigting nie, maar dat hul Christene is.

Die gevolgtrekkinge wat só gemaak is uit Tacitus se beskrywing. nl. dat die Christene onskuldig was, word ook onderstreep deur die feit dat Suetonius die mishandelinge nie eers in verband bring met die groot brand van Julie 64 n.C. nie.'")

Die derde probleemstelling ten gevolge van Tacitus se berig is, hoe kom Nero dan daartoe om die Christene die misdaad aan te vryf?

Daar is sommige wat oordeel dat die Jode Nero op die Christene aangeset het; ") om van die owerheid gebruik te makk teen die Christene

39) vgl. Furneaux, op. cit. p. 374 n.ad loc. and p. 416 ff.

40) Suet. De Vita Caes. Nero 16.

1) Gibbon. op. cit. p. 394; Bury. A History of the Roman Empire, Lond. 1922 ${ }^{7}$, p. 288. 
is nie sonder analoog in die geval van die Jode nie." ) Die moontlikheid bestaan dat die moordlus van die Keiser in die eerste instansie teen die Jode kon ontbrand, aangesien net die stadsdeel wat deur hulle bewoon is, nl. die Transtibereense streek, nie deur die brand beskadig is nie. Vorige keisers het ook nie gewag om die Jode van die stad te straf nie. ${ }^{\star 3}$ )

Gibbon sien die moontlikheid dat 'n Joods-rebellistiese faksie, bekend as "Galileërs" verwar is met die Christene wat onder dieselfde naam bekend was. ${ }^{4}$ ) Die keiser sou dan aanvanklik voornemens wees om die Jode as rebelle te straf maar hulle het die nasionale gevaar in 'n godsdienstige voordeel verander deur die keiser se aandag af te lei op die Christene, deur hulle só gehaat. Meestal in goeie guns aan die hof. sou hul maklik in so 'n plan kon slaag. ${ }^{+5}$ )

Voorspraak aan die hof het hul ook nie ontbreek nie. Poppaea Sabina was 'n Jodegenote en het al vantevore vir die Jode in die bres getree. ${ }^{46}$ ) Dit was ook die geval met die gunsteling, die nar Aliturus wat 'n Jood was. ${ }^{47}$ ) Van verder nut in dié verband kon Epaphroditus gewees het; begunstig deur Nero, was hy ook 'n intieme vriend van die Joodse geskiedskrywer, Josephus. ${ }^{48}$ )

Hierdie sienswyse stuit egter op baie besware af :

i. Die onreg deur in reeds algemeen gehate Nero sou te groot gewees het as hy 'n sondebok gekies het wat nie die vulgus nie, maar slegs die Jode genoeë gedoen het.

ii. Tacitus, hoe kernagtig sy styl ookal, sou só 'n stukkie geskiedenis nie onbenut gelaat het om sy uitgesproke antisemitisme te lug nie. Hierdie argument geld ook van Suetonius.

iii. Clemens in sy Corinthe-brief en Tertullinnus, in sy npologie, sou dit beslis ook gemeld het.

iv. Petronius, 'n gunsteling van Nero, wat net twee jaar na die brand in onguns geval het en beveel is om selfmoord te pleeg, het sy laaste ure gebruik om 'n naakte relaas van Nero se misdade te boekstaaf in sy Satyricon; hy sou ongetwyfeld melding moes maak van só 'n gebeurtenis veral daar hy die gesel ook swaai oor die vulgêre nouveau riche.

v. Die valse Seneca-Paulus-Korrespondensie (brief 12) het in die opsig waarde dat dit nog in die tyd van die vervalser

12) vgl. Hnd. 18:12 ff.

43) vgl. Bury. op. cit. p. 194. vir Tiberius se optrede teen hulle. Suet. Claud.us, 25 vertel van hul verbannina deur Claudius.

14) vgl. Gibbon. op. cit. p. 394 ff.

15) vgl. Dill. Roman Society from Nero to M. Aure ius, London, 19257, p. 83.

+6) vgl. Bury, op. cit. p. 288 en Dill op. cit. p. 83.

i) vgl. Gibbon. op. cit. p. 394 en Josephus. De Vita Sua. c. 3.

18) vgl. Furneaux. op. cit. note on Ann. 15.55.1. 
bekend was dat Nero saam met die Christene ook Jode gemartel het.

Die enigste aanneemlike verklaring is dat die Christene self, deur hul belydenis en geloofsuitlewing in algemene onguns geraak, aan Nero die geleentheid gebied het om hulle as die mees voor die hand liggende sondebok te verklaar en dienooreenkomstig te straf.

Solang die Christendom nog deur die staat vereenselwig was met die Jodendom, 'n religio licita, het hul van staatsweë eerder beskerming as teenkanting ondervind. Uit dié oorweging het Paulus hom ook op die keiser beroep. ${ }^{49}$ )

Toe die onderskeid tusseil hulle egter duidelik geword het, het die houding van die owerheid teenoor die Christene ongunstig verander en gedurende die drie volgende eeue ongunstig gebly.

Terwyl dit nie uitgeslote is nie dat Joodse verdagmakery bygedra het tot die veranderde houding. was dit tog op die lange duur suiwer maatskaplike en staatkundige oorwegings wat die optrede teenoor die Christene bepaal het.

Dr. G. J. D. Aalders meen dat die verbanningsedik van Claudius gemik was teen die Christendom wat toe al as staatsgevaarlik beskou is. ${ }^{30}$ ) Die vroegste teenkanting teen die Christendom het egter nie van die owerheid nie, ruaar uit die volk gekom. Die beskuldiging van $H$ nd. $16: 20$ en 21 sal wel meermale deur die bevolking herhaal gewees het. Grotendeels van Joodse herkoms, het die Christene ongetwyfeld ook gedeel in die algemene onguns waarin daardie volk by die Romeine. gestaan hẹt. In die verband is dit opvallend dat Tacitus die Christene van haat teen die menslike geslag beskuldig, 'n veroordeling wat hy ook oor die Jode uitspreek. ${ }^{51}$ )

Die ou romeinse godsdiens, deur Augustus in ere herstel en deur sy opvolgers gehandhaaf, is ty die bevolking met groot akklamasie ontvang; die alledaagse gebruike is eindelik só deurweef met die godsdiens dat ' $n$ Christen hom alleen deur die mees besliste onttrekking aan die maatskappy kon vrywaar teen afgodediens. ${ }^{.2}$ ) Daardeur is egter die haat van die Romeine teen hom gaande gemaak en boënop nog vererger deur die valsa voorstellinge oor die Christelike belydenis en geloofslewe.

Die verhouding sou wel nie verbeter het deur die sombere boeten oordeelsprediking van die Christene in hul sendings-ywer nie. Paulus se verblyf in Rome, nie baie jare vóór die brand nie, het ongetwyfeld die bestaande. verskille benadruk en die aantal Christene só laat toeneem dat hul in die ooglopend geword het.

19) Hnd. 25:11 vgl. MacKinnon. From Christ to Constantine, Edinburgh, 1938, p. 124. 125.

so) Dr. G. J. D. Aalders, Het Romeinsch Imperium en hat Nieuwe Testament, Kampen, 1938, bls. 61.

51) Tac. Hist. 5.5.2.

52) vgl. Gibbon, op. cit. p. 342 . 
In hierdie opsigte is egter alleen nog die argwaan van die volk gaande gemaak; ".staatsgevaarlik" het die Christene eers geword toe dit aan die lig gekom het dat hul weier om te sweer by die genus van die keiser en om militêre diens te verrig. Daarna was 'n verdraagsame houding van die owerheid teenoor hulle ook vir goed beëindig en het dit 'n misdaad geword gelykstaande aan majesteitskennis as iemand erken dat hy 'n Christen is. Dit is trouens die implikasie van Tacitus se woorde, ,igitur primum correpti qui fatebuntur." Te een of ander tyd sou die owerheid dus noodwendig teen die Christene moes optree.

Onder Nero het die onvermydelike slag geval. Reeds gebrandmerk en deur die volk gehaat, het 'n toevallige gebeurtenis, die groot brand van Julie 64 n.C., hul onder die aandag van die keiser gebring as in geskikte voorwerp waarop hy die algemene verdenking teen sy persoon af kon lei. Die haat van die volk het Nero gesmoor in die . Christene se bloed.

A. S. GEYSER. 